\title{
Los sistemas de rentas mínimas: protección social, ciudadanía y clientelismo político. Un análisis comparado entre Andalucía y Castilla y León ${ }^{1}$
}

\section{Javier Pacheco-Mangas}

Servicios Sociales Comunitarios, Ayuntamiento de Vélez-Málaga (Málaga)

\author{
Arantxa Hernández-Echegaray \\ Servicios Sociales Básicos, Ayuntamiento de Palencia \\ Dpto. de Sociología y Trabajo Social, Universidad de Valladolid \\ <ahernandez@aytopalencia.es>
}

\begin{abstract}
Gutxiengo errenta-sistemak oinarrizko sostengu gertatzen dira ongizate-ekonomia kapitalistetan eta giltzarri dira politika sozialak legitimatzeko ahultasun sozial handiko garai honetan. Artikulu honetan aztertzen dira Andaluzia eta Gaztela eta Leongo sistemak, eta xede hartzen du Administrazioak burutzen duen gizartebazterketaren eraiketara hurbiltzea, eta hausnartzea politika sozialaren segiziozale diren sistemen inguruan. Ikuspegi kualitatibo bat oinarri harturik, Wetherell eta Potter (1996) adituen araberako dokumentu-iturrien azterketaren bitartez, emaitzek erakusten dute edukiari dagokionez bi erkidego autonomo horien arteko aldeak zeintzuk diren, adibidez, prestazioa lortzeko betebehar eta sarbidearen inguruan. Bi erkidegoetan azaltzen dira arlo komunitarioko lana sendotzeko premia, arrakasta bermatzeko jarraipen indibidualak eta babes-sisteman inplikaturiko eragile horien guztien arteko koordinazioa hobetzeko premia.
\end{abstract}

\section{GAKO-HITZAK:}

Gutxiengo errenta-sistemak, gizarte-langintza, eskuartze komunitarioa, diskurtsoaren azterketa.
Los sistemas de rentas mínimas constituyen un soporte esencial en las economías capitalistas del bienestar y son clave en la legitimación de las políticas sociales en momentos de gran vulnerabilidad social. El presente artículo, que analiza estos sistemas en Andalucía y Castilla y León, tiene como objetivos aproximarnos a la construcción del fenómeno de la exclusión que lleva a cabo la Administración y reflexionar sobre los sistemas clientelistas de política social. Desde un enfoque cualitativo, mediante el análisis de fuentes documentales, de acuerdo con la propuesta de Wetherell y Potter (1996), los resultados ponen de relieve las diferencias entre esas dos comunidades autónomas en cuanto al contenido, requisitos y acceso a la prestación, entre otras cuestiones. En ambas comunidades aparecen aspectos que indican la necesidad de reforzar el trabajo comunitario, el seguimiento individualizado para garantizar el éxito y una mayor coordinación de todos los agentes implicados en los sistemas de protección social.

\section{Palabras ClaVe:}

Sistemas de rentas mínimas, trabajo social, desafíos, intervención comunitaria, análisis del discurso. 


\section{Introducción}

\section{1. ¿Dónde está el Estado (pro)social?}

El Estado sociopolítico europeo resultante de la crisis económica ha supuesto un revulsivo a los Estados de bienestar concebidos hasta el momento. Se han alzado voces que empleaban expresiones tales como 'Estado del medio estar”, 'del malestar' o ‘fin del Estado de bienestar’: “Deja de hablarse de Estado de bienestar y en su lugar se habla de sociedad del bienestar [...], indicando que es la sociedad la que tiene que procurarse su propio bienestar. La sociedad es un concepto abstracto, es un esencialismo. Realmente serán los individuos concretos los que tendrán que procurarse su propio bienestar" (Barrera-Algarín et al., 2013: 119-120). No son meros cambios lingüísticos, y tras ellos se encierran formas distintas de articular los derechos y la protección social a la ciudadanía.

El sustrato que subyace es una convergencia política hacia formas neoliberales de configuración de los asuntos privados como asuntos exclusivamente privados, negando su dimensión pública o colectiva. Sin duda, los Estados sociales actuales han alcanzado un calado, un arraigo y una legitimidad social como ninguna otra forma precedente de organización político-económica y social de gobierno había logrado. Prueba de ello son los gestos ciudadanos, muchos gestados en nuestro país y con expansión y proyección internacional, que han surgido ante el sentimiento de lesión y vulneración de los derechos sociales, y que reivindican la dignidad básica de los ciudadanos.

La relación entre ciudadanía y Estados de bienestar se han constituido como una realidad indisoluble desde su concepción, y en progresión, desde las tesis de Marshall en 1949 (Marshall, 1997) hasta la 'ciudadanía precaria' de Luis Moreno (2000). Marshall traza un camino que construye la ciudadanía a partir de los derechos civiles, políticos y sociales. De estos últimos nace la responsabilidad pública en los asuntos sociales del área privada y las bases de los Estados sociales. Tezanos (2008) da un salto cualitativo, a través de la noción de 'ciudadanía económica’, que podemos entender como una cuarta etapa de derechos de la ciudadanía. La ciudadanía económica implica la puesta en marcha "de servicios sociales más amplios y universales (como cuarto pilar efectivo del Estado de bienestar), de políticas que hagan accesibles la vivienda y de salarios sociales o rentas de inserción [...]. El objetivo que debemos plantearnos es una resocialización general de lo económico" (ibídem: 27), "la unicidad social, de forma que todos los ciudadanos puedan alcanzar un sentido equiparable de pertenencia a la comunidad y de dignidad en sus modos de vida" (ibídem: 26). Ello supone trascender una ciudadanía subvencionada, basada en ingresos garantizados y en la pasividad, y promover una actividad socialmente útil, que expande una conciencia cultural, colectiva e inclusiva de la ciudadanía.
La satisfacción de las necesidades básicas es el factor legitimador de la intervención pública directa. Muchas veces, esta actuación constituye "la única materialización de sus derechos de ciudadanía” (Moreno, 2000: 55). Es por ello por lo que los sistemas de rentas mínimas se convierten en la 'última red' de protección y un elemento necesario de los Estados de bienestar; un indicador y medidor de salud de los Estados de bienestar, podemos decir. Tanto es así que Moreno (2012: 119) sostiene que "las últimas redes o mallas de seguridad de protección social se configuran como entramados institucionales que plasman el grado de civilización y desarrollo alcanzado por sus respectivas sociedades, y son exponentes del grado de solidaridad comprometida por sus ciudadanos".

Con todo, el desarrollo y el contenido de las rentas mínimas es diverso y heterogéneo, tanto si lo analizamos en el tiempo como en el contexto. Existen dos líneas de concepción de las rentas mínimas, las denominadas 'de ciudadanía' y las 'de base'. No se ha desarrollado un sistema de rentas garantizadas a modo de renta básica, y las políticas sociales han incorporado unas rentas de base para la cobertura de las necesidades básicas y materiales, tendentes, cada vez más, hacia la universalidad. La financiación no tiene una naturaleza contributiva, sino que más bien corre por cuenta de una estimación política alzada a través de los presupuestos. Las rentas mínimas son una forma de solidaridad social ciudadana que recoge la esencia de reincorporación en la vida social y ciudadana, de retroalimentar el imaginario colectivo, la conciencia comunitaria, y la pertenencia y la participación en lo público. Pueden tener una lectura bien distinta si se emplean como recurso político para mantener un orden o una "paz social" (Moreno, 2000: 62), o si se sustentan en el "fundamento moral de compasión ciudadana” (ibídem: 65), en vez de en el derecho subjetivo efectivo y real.

En este sentido, la actuación profesional del trabajador o de la trabajadora social es clave como elemento dinamizador del capital personal y social de la ciudadanía y de la comunidad. En efecto, muchas veces hemos de contextualizar a las personas perceptoras de estas prestaciones y emprender acciones globales e integrales de índole comunitaria. La intervención social ha de llegar y cubrir los déficits de estas políticas, pues en algunos casos "se han tejido de manera incompleta, dejando huecos por los que se deslizan algunos ciudadanos con mayor grado de precariedad" (Moreno, 2012: 121)

Un riesgo básico es que el desarrollo de nuestra disciplina va unido al desarrollo de los derechos sociales y a la inversión en las políticas sociales (Barrera-Algarín et al., 2013). Para el trabajo social y para su intervención en los contextos más desfavorecidos y vulnerables, ello ha de suponer un reto y no un obstáculo. La vinculación entre trabajo social y pobreza/exclusión es histórica. El trabajo social actual tiene mucho a favor para hacer frente a los desafíos actuales que plantea el desmantelamiento 
de los servicios sociales y las transformaciones en los Estados de bienestar.

Consideramos que los Estados de bienestar, si bien adoptando otras formas, pervivirán, por haber conjugado el conflicto y las desigualdades sociales con el acceso a los derechos sociales y a la participación de todas las capas sociales. Sin duda, las prácticas pretéritas, las actuales y las que prevemos para el futuro tendrán sus luces y sus sombras, pero partimos de que iniciamos una nueva era del Estado de bienestar, en la que será necesario revisar los siguientes puntos, que consideramos ejes claves en el momento actual:

- La reconstrucción de los derechos sociales. El gasto en protección social es una inversión en el futuro de una sociedad.

- La protección de la atención a las capas sociales afectadas por la crisis y a las más vulnerables. Ello se traduce en el refuerzo de un sistema público de servicios sociales de índole local.

- La recuperación de una conciencia colectiva y comunitaria. Se hace necesario acercar estos actores, política y ciudadanía, pues en la actualidad hay una importante desafección, y una falta de participación ciudadana y de responsabilidad política real en los asuntos públicos.

A continuación y siguiendo estos tres ejes de forma dialéctica y no lineal, vamos a concretar las tesis objeto de nuestra investigación:

a. El distanciamiento de hecho de las políticas sociales de la ciudadanía.

b. El tratamiento a las situaciones de pobreza y exclusión en las políticas públicas autonómicas; en particular, en Andalucía y Castilla y León.

c. El refuerzo de la profesión del trabajo social ante los espacios vacíos dejados por la Administración.

\section{2. ¿Pobreza o nueva pobreza? El distanciamiento de hecho de las políticas de la ciudadanía}

Las políticas de austeridad y las reformas normativas han lesionado profundamente los derechos de la ciudadanía y han truncado el pacto o consenso social, a consecuencia de la movilización socioeco- nómica descendente de las capas sociales medias. La fórmula socioeconómica de los Estados de bienestar favoreció la expansión y creación de una clase social 'media', que ha sido una de las principales víctimas de la crisis económica. El empobrecimiento de la ciudadanía y de las clases medias es un hecho social constatado. Ello provoca una movilidad social descendente, que bloquea la movilidad y la emancipación social de los futuros ciudadanos, los jóvenes.

Los jóvenes españoles tienen las tasas de desempleo juvenil más altas de Europa. La falta de políticas sociales que promocionen a este grupo etario o le ayuden a salir de esa situación genera una dependencia económica de sus progenitores. Todo ello trae como consecuencia un fenómeno doble de empobrecimiento familiar, dadas las dificultades de inserción laboral y la pérdida de empleo de personas de mediana edad (Tezanos et al., 2013). Estos nuevos perfiles empiezan a engrosar los listados de perceptores de rentas mínimas. A los servicios sociales de base acuden personas que manifiestan no haberlo hecho nunca anteriormente. Ni para el trabajo social ni para los servicios sociales es una novedad, pero se plantea una cuestión clave: ¿está el sistema preparado? En este sentido, Laparra y Pérez Eransus (2010: 469) sostienen que "la crisis ha puesto en evidencia la debilidad de un sistema inacabado y fragmentado".

Esta situación de empobrecimiento, que a pesar de su apariencia coyuntural propia de la situación socioeconómica actual, puede desembocar en situaciones de exclusión estructural que lesionen la cohesión social. A ello se le unen los perceptores crónicos o habituales de estas prestaciones. Siendo perfiles diferentes, requieren intervenciones sociolaborales diferenciadas, $y$, en el caso de los primeros, intervenciones preventivas de la exclusión. Con todo, Luis Moreno (2012: 117) señala que:

La inclusión de los ciudadanos en los circuitos sociales no siempre es posible por la vía de la integración laboral. En el caso de los ciudadanos precarios y en dificultades, esto tan solo es factible mediante la acción de instituciones y políticas de solidaridad colectiva como las del Estado de bienestar. En realidad, la integración laboral suele ser inviable no sólo en lo que respecta a los pobres

\begin{tabular}{|c|c|c|c|c|}
\hline \multicolumn{5}{|c|}{ Cuadro 1. El camino de los derechos en la construcción de la ciudadanía } \\
\hline MARSHALL (1949) & $\begin{array}{l}\text { Civiles } \\
\text { (s. XVIII) }\end{array}$ & $\begin{array}{l}\text { Políticos } \\
\text { (s. XIX) }\end{array}$ & $\begin{array}{c}\text { Sociales } \\
\text { (s. XX) }\end{array}$ & \multirow{3}{*}{ Humanos } \\
\hline TEZANOS (2008) & \multicolumn{3}{|c|}{ Ciudadanía económica } & \\
\hline MORENO (2000) & \multicolumn{3}{|c|}{ Ciudadanos precarios } & \\
\hline \multicolumn{5}{|c|}{ Estados de bienestar } \\
\hline \multicolumn{2}{|c|}{ Servicios sociales } & \multicolumn{3}{|c|}{ Trabajo social } \\
\hline \multicolumn{5}{|c|}{ Acciones correctoras } \\
\hline
\end{tabular}

Fuente: Elaboración propia. 
marginados o permanentes que carecen de capacidades básicas para mejorar su situación, sino también en aquellos desempleados en tránsito entre crisis económicas o situaciones de paro estructural.

Un riesgo evidente es la reforma del régimen local (Ley 27/2013, de 27 de diciembre), que deslocaliza la atención en los servicios sociales en el nivel más próximo a la ciudadanía. La Ley $7 / 1985$, de 2 de abril, preveía, en su articulado, la gestión de aquéllos por las entidades locales. La descentralización hacia esta Administración no sólo no ha tenido lugar, sino que se ha producido un efecto estabilizador en el ámbito regional: "La actual ley se aleja de un marco de ciudadanía para profundizar en un marco más propio de la beneficencia local y de la asistencia social que se estructuró en España a partir de la primera Ley de Beneficencia de 1822" (Uceda et al., 2014: 250). Otro riesgo que entraña esta reforma es la deslocalización de los procesos de inclusión. La integración sociolaboral de los perceptores de rentas alcanza mayor éxito, y tiene su razón de ser, si se lleva a cabo dentro del contexto social y natural propio de la persona o familia perceptora. De ahí la importancia de mantener las políticas sociales de integración en el ámbito de la proximidad local.

\subsection{El tratamiento de la pobreza y la exclusión en las políticas públicas autonómicas. Análisis del caso de Andalucía y Castilla y León}

En este escenario, los sistemas de rentas mínimas han adquirido una gran relevancia social, pues, como señala Moreno (2012: 119-120), “en la Unión Europea, se ha consensuado un acuerdo sobre la necesidad de reorientar las políticas sociales para combatir la exclusión social. Ello se ha producido a nivel estatal (renovación y aparición de nuevas políticas de tipo asistencial) y europeo (programas comunitarios de lucha contra la pobreza)".

En Castilla y León, las rentas mínimas se implantan por primera vez con la aprobación del Decreto 132/1990, como 'prestación económica de integración social'. Tiene una vigencia corta, ya que es derogado por el Decreto 286/1991, que instaura el 'ingreso mínimo de inserción'. Éste se mantiene vigente hasta el Decreto 164/1997, que es sustituido por el Decreto 197/2000, y éste último, a su vez, por el Decreto 126/2004. La Ley 7/2010, que aprueba la 'renta garantizada de ciudadanía', abre el espacio actual y su desarrollo se concreta en el Decreto 61/2010. El Decreto Ley 2/2013 introduce mejoras, como medidas extraordinarias de apoyo a las familias afectadas por la crisis en situación de vulnerabilidad o exclusión social. Finalmente, el Decreto Legislativo 1/2014 aprueba el texto refundido de las normas vigentes reguladoras de la prestación esencial de renta garantizada de ciudadanía. Las principales mejoras introducidas en esta sucesión normativa han sido:

- La creación de perfiles, a través de la concreción de los requisitos.

- El refuerzo del papel de la inserción, mediante la vinculación a un proyecto individualizado de inserción.

- La mejora en la cuantía económica.

En Andalucía, las rentas mínimas autonómicas comienzan con la puesta en marcha del Programa de Solidaridad para la Erradicación de la Marginación y la Desigualdad en Andalucía, también en 1990, un ambicioso programa integral que pretende luchar contra la exclusión en la comunidad autónoma, orientando su principal acción a un programa de mantenimiento de ingresos a través de una importante colaboración interadministrativa, principalmente en el ámbito de las propias competencias autonómicas, aunque implica también a las entidades locales que entonces comienzan el desarrollo de los servicios sociales comunitarios. A finales de la década, el Decreto 113/1998, crea una comisión que tiene como principal tarea la reforma del Programa de Solidaridad y que fructifica en el Decreto 2/1999 de 12 de enero, que se ha mantenido vigente, con algunas modificaciones menores, hasta fechas recientes, cuando el Decreto Ley $7 / 2013$, de 30 de abril, introduce algunas innovaciones de cierto calado.

Si existe un rasgo diferenciador entre los dos sistemas de rentas mínimas, es el carácter de prestación

\begin{tabular}{|l|l|l|}
\hline \multicolumn{2}{|l|}{ Cuadro 2. Hitos normativos de los sistemas de rentas mínimas en Andalucía y Castilla y León } \\
\hline Años & Andalucía & Castilla y León \\
\hline 1990 & Decreto $400 / 1990$, de 27 de noviembre & Decreto $132 / 1990$, de 12 de junio \\
\hline 1991 & & Decreto $286 / 1991$, de 3 de octubre \\
\hline 1997 & & Decreto $164 / 1997$, de 22 de agosto \\
\hline 1998 & Decreto $113 / 1998$, de 2 de junio & \\
\hline 1999 & Decreto $2 / 1999$, de 12 de enero & \\
\hline 2000 & & Decreto $197 / 2000$, de 21 de septiembre \\
\hline 2004 & & Decreto $126 / 2004$, de 30 de diciembre \\
\hline 2010 & & $\begin{array}{l}\text { Ley } 7 / 2010, \text { de } 30 \text { de agosto y Decreto } 61 / 2010, \text { de } 16 \text { de } \\
\text { diciembre }\end{array}$ \\
\hline 2013 & Decreto Ley $7 / 2013$, de 30 de abril & Decreto Ley $2 / 2013$, de 21 de noviembre \\
\hline 2014 & & Decreto Legislativo $1 / 2014$, de 27 de febrero \\
\hline
\end{tabular}

Fuente: Elaboración propia. 
esencial que otorga en Castilla y León la Ley 7/2010, la cual aprueba la renta garantizada de ciudadanía, y que, a diferencia de lo que ocurre en Andalucía, convierte a la prestación económica del sistema de rentas mínimas en un derecho subjetivo. Esta norma marca tres diferencias sustanciales respecto a sus antecesoras:

- Se aprueba mediante ley, al responder a un derecho subjetivo.

- Se estructura la intervención desde la consideración de que la unidad familiar atraviesa una situación de exclusión de carácter estructural o coyuntural.

- La información y la gestión se trasladan desde los centros de servicios sociales dependientes de las entidades locales a las gerencias territoriales de servicios sociales de la Junta de Castilla y León.

Ello lleva asociadas tres consecuencias de gran importancia:

- Ante los recursos presupuestarios reducidos de un momento de crisis económica, en el que además se penaliza el endeudamiento de las administraciones públicas (según la última modificación del artículo 135 de la Constitución), queda como posibilidad regular los flujos de entrada y salida de las familias potencialmente beneficiarias, endureciendo los requisitos y las obligaciones contraídas por ser perceptoras de renta garantizada de ciudadanía.

- Si el control se ejerce desde un único órgano territorial, las entradas son menores que si se descentraliza a los centros de servicios sociales de atención primaria de índole municipal o provincial, en todo caso, local.

- Apertura a las situaciones temporales de carencia de rentas, como red subsidiaria del sistema de rentas de corte contributivo o asistencial.
En el Cuadro 3, se pueden apreciar los principales rasgos de las rentas mínimas en las dos comunidades autónomas analizadas, basándonos en la siguiente revisión de la normativa vigente:

- Para Andalucía: Decreto 2/1999, de 12 de enero, por el que se regula la creación del Programa de Solidaridad de los andaluces para la erradicación de la marginación y la desigualdad; modificado por el Decreto Ley 7/2013, de 30 de abril, de medidas extraordinarias y urgentes para la lucha contra la exclusión social en Andalucía.

- Para Castilla y León: Decreto Legislativo 1/2014, de 27 de febrero, por el que se aprueba el texto refundido de las normas legales vigentes en materia de condiciones de acceso y disfrute de la prestación esencial de renta garantizada de ciudadanía de Castilla y León; y el Decreto 61/2010, de 16 de diciembre, por el que se aprueba el reglamento de desarrollo y aplicación de la renta garantizada de ciudadanía.

La situación actual de crisis económica ha tenido repercusiones importantes en el ámbito de los sistemas de rentas mínimas analizados. Así, desde $\mathbf{2 0 0 8}$, en ambas comunidades autónomas se ha mantenido una tendencia alcista en el número de beneficiarios que continúa a día de hoy, si bien se producen diferencias significativas debido a su propia configuración. En Castilla y León, vemos cómo el principal aumento de beneficiarios se produce a partir de 2011, tras la entrada en vigor de la norma autonómica que reconoce su universalidad, con un ascenso continuado y estable de los beneficiarios a partir de ese momento, que coincide con ejercicios de mayor precariedad debida a la crisis, tal y como puede apreciarse en el Gráfico 1.

Este último elemento también influye de manera significativa en el sistema de rentas mínimas de Andalucía, que ve incrementarse sus beneficiarios en todo el periodo estudiado. No obstante, la mayor

\begin{tabular}{|l|l|l|}
\hline \multicolumn{2}{|l|}{ Cuadro 3. Comparativa entre los sistemas de rentas mínimas de Andalucía y Castilla León } \\
\hline & Andalucía & Castilla y León \\
\hline Denominación & Ingreso mínimo de solidaridad. & Renta garantizada de ciudadanía. \\
\hline Rango legal & Decreto (reglamento). & Decreto legislativo (ley). \\
\hline Derecho & Sujeto a disponibilidad presupuestaria & Subjetivo. Prestación esencial. \\
\hline Límites de los requisitos & Ciudadanos que no pertenezcan a la Unión Europea. & $\begin{array}{l}\text { Documentación de bienes y rentas a inmigrantes con } \\
\text { traducción jurada. Patrimonio sin explotar. }\end{array}$ \\
\hline Plazos & $\begin{array}{l}\text { Dos meses. Devengo a últimos de mes. Concesión } \\
\text { con carácter provisional en situaciones de } \\
\text { emergencia social. }\end{array}$ & Tres meses. Devengo a últimos de mes. \\
\hline Penalización & Periodos de seis meses de carestía. & Seis meses y cobro indebido por incumplimiento. \\
\hline Cuantía & $\begin{array}{l}62 \% \text { del SMl, más } 8 \% \text { por cada miembro de la } \\
\text { unidad familiar, hasta el 10o\% del SMl. }\end{array}$ & $\begin{array}{l}\text { Desde el 8o \% del IPREM hasta el 130\%, según } \\
\text { miembros de la unidad familiar }\end{array}$ \\
\hline Duración & Máximo seis meses. & Indefinido. \\
\hline Complementos & Medidas educativas. Acceso a la vivienda. & Violencia, prestaciones, alquiler e hipotecas públicas. \\
\hline
\end{tabular}

SMI: Salario mínimo interprofesional. IPREM: Indicador público de renta de efectos múltiples.

Fuente: Elaboración propia. 


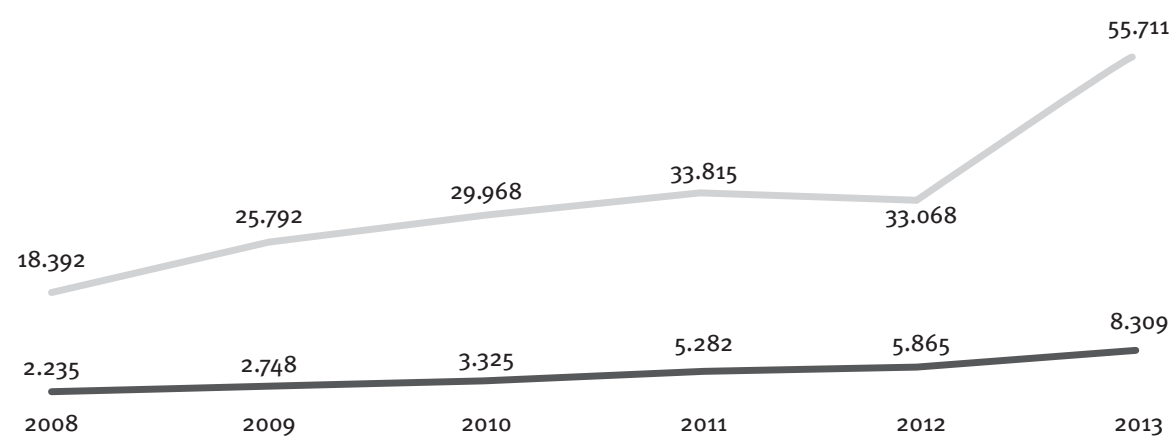

Castilla y León

Andalucía

Fuente: Elaboración propia a partir de datos estadísticos del Programa de Solidaridad de los Andaluces, cifras oficiales de población del Instituto de Estadística y Cartografía de Andalucía, y datos del Consejo Económico y Social de Castilla y León (2014).

Tabla 1. Perceptores de sistemas de rentas mínimas. Andalucía y Castilla y León, 2012-2013

\begin{tabular}{|l|c|c|c|c|c|}
\cline { 2 - 6 } \multicolumn{1}{c|}{} & \multicolumn{2}{c|}{ Cifras absolutas } & \multirow{2}{*}{ Diferencia (\%) } & \multirow{2}{*}{ Población } & $\begin{array}{c}\text { Perceptores por } \\
\text { cada 1.000 hab. }\end{array}$ \\
\cline { 2 - 6 } \multicolumn{1}{c|}{} & $\mathbf{2 0 1 2}$ & $\mathbf{2 0 1 3}$ & & & 6.40 \\
\hline Andalucía & 33.068 & 55.711 & 59,35 & 8.440 .300 & 3,60 \\
\hline Castilla y León & 5.865 & 8.309 & 41,67 & 2.519 .875 & 30 \\
\hline
\end{tabular}

Fuente: Elaboración propia a partir de datos estadísticos del Programa de Solidaridad de los Andaluces, cifras oficiales de población del Instituto de Estadística y Cartografía de Andalucía, y datos del Consejo Económico y Social de Castilla y León (2014).

incidencia para ambas comunidades se produce en 2013, con un aumento de prestaciones concedidas respecto al año anterior del 59,35\% en Andalucía y del $41,7 \%$ en Castilla y León, hecho que puede atribuirse a la mayor precarización, al final de la cobertura de otros programas de protección (principalmente relacionados con el empleo) y a la flexibilización de los requisitos introducidos por el Decreto Ley $7 / 2013$, de 30 de abril, en el caso de Andalucía.

\section{Material y método}

\subsection{Enfoque metodológico}

Se pretende hacer un análisis comparativo entre los programas de rentas mínimas de las comunidades autónomas de Andalucía (ingreso mínimo de solidaridad del Programa de Solidaridad de los Andaluces para la Erradicación de la Marginación y la Desigualdad en Andalucía) y Castilla y León (renta garantizada de ciudadanía).

El estudio parte de una metodología cualitativa, basada en el análisis del discurso según la propuesta de Wetherell y Potter (1996), que se articula a través de los conceptos de función, variabilidad, construcción y unidad analítica del repertorio interpretativo, aplicada aquí a información obtenida a través de fuentes documentales. Según los autores, la función define la orientación del lenguaje hacia la acción; el hablar con- lleva funciones como justificar, disculpar o explicar, pero a veces produce efectos que van más allá de la mera descripción y no están directamente disponibles para el analista. En cuanto a la variabilidad, los autores hacen referencia a que un acontecimiento o hecho social puede describirse de diversas formas, en la medida en que la función puede variar; es decir, cierto tipo de funciones nos pueden llevar a determinadas variaciones en el discurso. Por otro lado, la construcción sirve de guía para el análisis, mostrando los recursos lingüísticos disponibles para la conformación del discurso e insistiendo en el carácter performativo del lenguaje en tanto que éste tiene consecuencias prácticas. Por último, la unidad analítica del repertorio interpretativo establece los patrones de regularidad discursiva que se dan entre los hablantes y que "se pueden considerar como los elementos esenciales que los hablantes utilizan para construir versiones de las acciones, los procesos cognitivos y otros fenómenos" (ibídem: 66).

\subsection{Fuentes documentales}

La investigación se ha llevado a cabo mediante la recogida de datos de fuentes documentales (de tipo primario y fácil acceso). Ya que se trata de hacer un análisis de los repertorios interpretativos que permita observar la representación que realiza la propia Administración de la prestación y de sus beneficiarios, la identificación de las fuentes se ha centrado 
prioritariamente en tres categorías, que desglosamos a continuación:

- Las normas básicas que contienen el desarrollo de los programas de rentas mínimas:

- Decreto 2/1999, de 12 de enero, por el que se regula el ingreso mínimo de solidaridad en Andalucía, modificado por el Decreto Ley 7/2013, de 30 de abril, de medidas extraordinarias y urgentes para la lucha contra la exclusión social en Andalucía y la normativa de desarrollo.

- Decreto Legislativo 1/2014, de 27 de febrero, por el que se aprueba el texto refundido de las normas legales vigentes en materia de condiciones de acceso y disfrute de la prestación esencial de renta garantizada de ciudadanía de Castilla y León.

- Los documentos donde se reflejan los compromisos adquiridos por los beneficiarios de la prestación:

- En Andalucía, compromiso de inserción.

- En Castilla y León, proyecto individualizado de inserción.

- Materiales publicitarios o divulgativos confeccionados por la Administración competente para informar a la ciudadanía. En este caso, se examinaron las páginas web institucionales de información sobre las rentas mínimas, intentando analizar:

- Accesibilidad.

- Ruta para acceder a la información.

- Claridad de la información.

- Representación que ofrece del público objetivo al que va dirigido.

\subsection{Procedimiento}

La recogida de datos se ha realizado a partir de las fuentes documentales descritas en el apartado anterior. Para llevar a cabo el proceso de categorización y comparación, se utilizó un instrumento diseñado ad hoc para esta investigación, que recogía las siguientes variables: tipo de fuente, definición y objetivos de la prestación, contenido en términos económicos o materiales, duración del programa, definición(es) de los potenciales beneficiarios, mecanismos de coordinación interadministrativa para su puesta en marcha, colaboración o responsabilidad de entidades de la iniciativa social en el desarrollo del programa, y acciones de seguimiento y evaluación del cumplimiento de objetivos.

Para el análisis, se trata de extraer de los documentos, mediante una lectura minuciosa y reflexiva, la información que nos permita observar su comportamiento y los repertorios discursivos que ponen en práctica, mediante la aplicación de preguntas implícitas. Siguiendo a Ruiz Olabuénaga e Ispizua (1989), la lectura que realizamos de los documentos pasa a convertirse en una mezcla de entrevista y observación, aplicando procedimientos y técnicas de ambas. Definida la muestra documental, para la investigación utilizamos como unidad de análisis el párrafo, determinando que mediante lecturas sucesivas y exhaustivas de las fuentes documentales se seleccionaran aquellos que contuvieran o desarrollaran el descriptor de cada eje temático. El proceso de selección de los extractos se sometió a un proceso de revisión interjueces entre los dos investigadores que llevaron a cabo el estudio.

En la recogida de los datos, se procuró obtener secuencias extensas de texto que tuvieran en cuenta los ejes temáticos descritos anteriormente, de manera que pudiera observarse con la mayor amplitud posible toda la variedad discursiva existente. Como apoyo para el análisis, se ha utilizado el software Atlas.ti (versión 6) en la fase textual, a fin de organizar el texto completo de cada una de las fuentes utilizadas, identificar fragmentos significativos, así como construir códigos. Posteriormente, dentro de la fase de análisis conceptual, se utilizó el establecimiento de relaciones entre los distintos códigos presentes en el discurso.

En cuanto a las posibles limitaciones metodológicas de la investigación, es necesario resaltar que, por economía de tiempo, no se ha podido realizar un procedimiento que permitiera la puesta en común con investigadores externos de los repertorios interpretativos identificados, para garantizar una mayor fiabilidad y un menor sesgo.

\section{Resultados}

Los repertorios interpretativos obtenidos se corresponden con las pautas o patrones de regularidad que las fuentes del discurso mantienen a lo largo de éste, pese a su variabilidad. Se quiere, por tanto, reflejar cómo se pone en práctica cada uno de los repertorios planteados, su importancia en el relato discursivo, así como su relación con los planteamientos teóricos de la profesión, y con las normas y códigos éticos que rigen la actuación profesional en los sistemas de rentas mínimas. Después de analizar los discursos recogidos en las fuentes documentales, se encontraron tres repertorios interpretativos: a) el encantador de serpientes; b) el bajo coste de la paz social; y c) un camino en soledad.

\subsection{El encantador de serpientes}

La orientación de los sistemas de rentas mínimas analizados hacia un modelo de globalidad en la protección social que resulta excesivo y desconectado de la realidad es el primer repertorio que nos encontramos. De esta forma, el objetivo de la propia prestación se encamina hacia una función integradora y canalizadora de la acción protectora del resto de sistemas de protección social que intervienen con el ciudadano. La pretensión puede chocar con la falta de normas que regulen esa función global y que 
puede tener como resultado una política de sistemas de rentas mínimas de 'brindis al sol'. En los siguientes extractos, vemos cómo las normas de Andalucía y Castilla y León introducen, en su exposición de motivos, elementos inspiradores de una política de sistemas de rentas mínimas que centraliza y se orienta hacia la consecución del bienestar social sin articular medidas concretas:

Junto a ella [el ingreso mínimo de solidaridad] se podrán arbitrar otro tipo de acciones o medidas insertivas que desarrollen y capaciten a la unidad familiar beneficiaria. Es importante la orientación y función integradora de medidas como el empleo frente a medidas meramente asistenciales, así como la existencia de la medida de vivienda y educación que refuerza esa integralidad (Andalucía. Decreto 2/1999, de 12 de enero, exposición de motivos).

Una situación como la actual conlleva una dimensión de impacto adicional en la que aparecen nuevas formas de exclusión, nuevas situaciones de necesidad, en muchos casos asociadas a la pérdida de empleo y a la carencia de rentas, así como componentes también distintos en su génesis y manifestación, demandas diferentes, y procesos de desigual naturaleza y alcance, alejados de los hasta ahora más comunes o frecuentes. En la medida en que estos fenómenos deriven en situaciones emergentes en las que resulta comprometida la cobertura de las necesidades básicas de subsistencia, la regulación de la prestación habrá de adaptarse para poder dar una respuesta adecuada en todos los casos (Castilla y León. Decreto Ley 1/2014, de 27 de febrero, exposición de motivos).

Esta situación se contrapone al principio de subsidiariedad que las propias normas plantean en su articulado, por cuanto el carácter subsidiario rompe el espíritu integrador que debe tener una política de acción global como la que veíamos en los anteriores extractos. Así, el artículo 3.f del Decreto ley 1/2014, de 27 de febrero, dice:

Subsidiariedad: consideración de la renta garantizada de ciudadanía como la última red de protección respecto a cualquier otra prestación, de forma que se reconocerá cuando, una vez solicitadas todas las prestaciones a que pudieran tener derecho los destinatarios, se haya resuelto su no concesión o se haya agotado su percepción, a salvo de las excepciones establecidas para los supuestos de complementariedad (Castilla y León. Decreto Ley $1 / 2014$, de 27 de febrero, art. 3.f).

Otro aspecto interesante en el discurso de las fuentes analizadas, y que se contrapone a los principios universalizadores y de acceso global que veíamos anteriormente, es el relativo al modelo de familia que plantean. De esta forma, vemos, por un lado, cómo los requisitos de acceso y la recentralización de éstos hacia un sistema de protección estanco y circunscrito al territorio de la comunidad autónoma puede dificul- tar la puesta en práctica de esa orientación general y de protección global a la que ya hemos hecho referencia. Asimismo, el propio concepto de familia, más estático que el que encontramos en la realidad, también representa una dificultad, como podemos ver en los siguientes extractos:

1. Se entenderá por unidad familiar la constituida por dos o más personas que, conviviendo efectivamente en un mismo domicilio, estén relacionadas entre sí:

a) Por matrimonio u otra relación análoga debidamente acreditada.

b) Por lazos de parentesco por consanguinidad o por adopción hasta el segundo grado. El parentesco se computará en relación con el firmante de la solicitud, salvo en caso de matrimonio o relación análoga, en que se contará indistintamente desde cualquiera de los cónyuges o miembros de la pareja (Andalucía. Decreto 2/1999, de 12 de enero, art. 3).

1. A efectos de la renta garantizada de ciudadanía, se consideran unidades familiares o de convivencia, sin perjuicio de aquellos supuestos en que el titular sea destinatario único, las siguientes:

a) Dos personas unidas por matrimonio o relación estable y acreditada análoga a la conyuga.

b) Dos o más personas que convivan en el mismo domicilio y estén unidas por parentesco hasta el segundo grado de consanguinidad, afinidad o adopción.

c) Dos o más personas que convivan en el mismo domicilio en razón de tutela o acogimiento familiar (Castilla y León. Decreto Ley 1/2014, de 27 de febrero, art. 8).

De este concepto de unidad familiar, se deduce la propia naturaleza familiar de la prestación, que toma así como referencia una unidad de configuración social, la familia, que descarta o traslada a lo excepcional otro tipo de formas de convivencia que pudieran darse. Destacamos, por tanto, que la prestación económica que conlleva el sistema de rentas mínimas, elemento principal de la acción protectora de la Administración, comporte este carácter, como podemos ver en el siguiente extracto:

Hay que destacar, en primer lugar, su configuración como una renta familiar. Por ello, tanto su titular como los restantes miembros de la unidad familiar o de convivencia en la que se integra se convierten en destinatarios de la prestación, resultando ésta acomodada a las necesidades de cada uno de ellos, para los que, en su caso, se contemplarán, cuando sea necesario y posible, previsiones específicas en la programación de las acciones necesarias para promover su integración social (Castilla y León. Decreto Ley 1/2014, de 27 de febrero, exposición de motivos). 
Es importante destacar la presencia en el discurso de las fuentes consultadas de un intento de orientar los sistemas de rentas mínimas hacia un espacio de colaboración interadministrativa donde las entidades locales tengan un principal protagonismo. A pesar de que en algunos extractos podemos observar este principio inspirador, no ha terminado de concretarse en normas más específicas que lo desarrollen y que garanticen un trabajo holístico para la integración y el bienestar social de los ciudadanos:

Queda prevista la posibilidad de colaboración con otras Administraciones Públicas, especialmente con la Administración Local, en el caso de ésta por su cercanía al ciudadano y la radicación en ella de los Servicios Sociales Comunitarios. En esta línea, se desea una mayor implicación y participación de los mismos en la gestión y seguimiento del Programa de Solidaridad (Andalucía. Decreto 2/1999, de 12 de enero, exposición de motivos).

2. Las entidades locales con competencias en materia de servicios sociales dispondrán la colaboración de los profesionales de los centros de acción social (CEAS) y equipos específicos que de ellas dependan en las actividades de estudio e informe de casos en las situaciones susceptibles de ser calificadas de exclusión social estructural, así como en la elaboración, desarrollo y seguimiento del proyecto individualizado de inserción, y en el seguimiento de la prestación ya reconocida en los supuestos así considerados (Castilla y León. Decreto Ley 1/2014, de 27 de febrero, art. 31.2).

\subsection{El bajo coste de la paz social}

Las economías capitalistas de bienestar promueven sus políticas sociales con una clara orientación de paz social. En ocasiones las coyunturas económicas y las dinámicas sociales elevan dicho coste, haciendo que determinadas políticas puestas en marcha no consigan los objetivos que se plantean. Las estrategias políticas que pretenden la mayor optimización y visibilidad de las partidas presupuestarias pueden estar también detrás de esta lógica de funcionamiento. En relación con los sistemas de rentas mínimas que estamos analizando, es posible que las medidas puestas en marcha no terminen de conseguir el objetivo para el que estaban diseñadas, en especial porque el discurso que promueven clasifica en una determinada categoría social a quienes las solicitan o acceden a ellas. Aquí hay que resaltar las importantes diferencias entre Andalucía y Castilla y León, con un discurso más restrictivo la primera, y más amplio la segunda, como podemos comprobar a través de los siguientes extractos:

El Ingreso Mínimo de Solidaridad (Salario Social) es una prestación económica mensual dirigida a las unidades familiares más desfavorecidas (Andalucía. Página web del Programa de Solidaridad).
La Renta Garantizada de Ciudadanía se configura como una prestación social y familiar de naturaleza económica y percepción periódica, cuya finalidad es atender las necesidades básicas de subsistencia y promover la integración de quienes se encuentren en situación de exclusión social (Castilla y León. Página web de la renta garantizada de ciudadanía).

En relación con esto, los sistemas de rentas mínimas analizados establecen unas cuantías, basadas en indicadores estandarizados, que quedan lejos de las demandas del mercado para la cobertura de las necesidades básicas de subsistencia, incluida la vivienda. De esta forma, el perfil del solicitante óptimo se restringe, lo que podría conllevar una menor incidencia en las clases medias y provocar desánimo a la hora de iniciar el procedimiento para su reconocimiento:

Disponer de unos recursos mensuales inferiores a la cuantía del Ingreso Mínimo de Solidaridad, calculada conforme establece el artículo 6.1 del presente Decreto, si bien tomando como referencia el Salario Mínimo Interprofesional vigente en la fecha de presentación de la solicitud (Andalucía. Decreto 2/1999, de 12 de enero, art. 2).

Se entenderá que existe una situación de carencia de medios económicos y patrimoniales cuando concurran todas y cada una de las siguientes circunstancias: a) que la suma de los ingresos mensuales de todos los posibles destinatarios sea inferior a la cuantía vigente de la renta garantizada de ciudadanía a que se pueda tener derecho, incluyendo los complementos previstos que en su caso pudieran corresponder cuando exista unidad familiar o de convivencia [...] (Castilla y León. Decreto Ley 1/2014, de 27 de febrero, art. 12).

Esto debe hacer que nos replanteemos cuestiones que van más allá de los sistemas de rentas mínimas analizados. Una de estas cuestiones es la utilidad real de los índices e indicadores estadísticos que usamos para determinar el acceso a una determinada prestación o subsidio, los cuales tienen efectos también sobre los salarios y el mercado de trabajo en general. Los siguientes extractos del relato que forman las fuentes analizadas detallan las cuantías que han de percibir quienes cumplan los requisitos de acceso al programa:

1. El Ingreso Mínimo de Solidaridad consistirá en una prestación económica mensual del 62 por 100 del Salario Mínimo Interprofesional vigente en la fecha de resolución de la solicitud, incrementada en un 8 por 100 por cada miembro de la unidad familiar distinto del firmante de la misma, hasta un máximo equivalente al 100 por 100 de dicho Salario Mínimo Interprofesional.

2. Los recursos computables de la unidad familiar reducirán la cuantía mensual de la prestación, sin que, como consecuencia de ello, pueda resultar ésta inferior al 15 por 100 del citado 
Salario Mínimo Interprofesional (Andalucía. Decreto 2/1999, de 12 de enero, art. 6.2).

La cuantía básica mensual de la prestación de la renta garantizada de ciudadanía estará cifrada en el ochenta por ciento del indicador público de renta de efectos múltiples (IPREM) vigente en cada ejercicio económico [...]. La cuantía máxima de la prestación a percibir será del ciento treinta por ciento del IPREM (Castilla y León. Decreto Ley $1 / 2014$, de 27 de febrero, arts. 15 y 19).

\subsection{Un camino en soledad}

El último repertorio identificado nos permite extraer los patrones de regularidad discursiva relacionados con el proceso de integración y prevención de la exclusión social que pretenden favorecer los sistemas de rentas mínimas analizados. Si bien éstos detallan múltiples instrumentos destinados a tales fines, en la práctica, y de forma particular en el proceso de coproducción y compromiso con los beneficiarios, se convierte en un camino que recorren de forma individual, sin ayuda. Los extractos que a continuación mostramos sirven para ilustrar esta línea argumental del repertorio, basada en los compromisos que deben suscribir los perceptores, así como en el contenido normativo obligacional:

Ámbito personal y familiar: escolarización y asistencia regular de todos los menores en edad escolar a mi cargo; asistencia regular y con aprovechamiento a los cursos de Educación de Adultos.

Vivienda: adoptar las medidas que permitan unas condiciones materiales e higiénico-sanitarias adecuadas a su uso [...].

Ámbito socioeconómico y laboral: aceptar ofertas de empleo adecuadas; asistir regularmente y con aprovechamiento a los cursos de Formación Profesional Ocupacional que me sean ofrecidos; colaborar en los proyectos de economía social y de inserción en los que sea llamado [...] (Andalucía. Compromiso de inserción del Programa de Solidaridad).

Son obligaciones generales de todos los destinatarios: a) cumplir el compromiso genérico de participación activa para superar la situación de necesidad y destinar la prestación concedida a la finalidad prevista en el artículo 5.1; b) facilitar la actuación de los técnicos para evaluar su situación y las posibles modificaciones futuras, así como para efectuar el seguimiento y evaluación de la prestación; c) solicitar todas las prestaciones referidas en el artículo 4.2 a las que pudieran tener derecho; d) no rechazar oferta de trabajo, así como mantener la inscripción como demandantes de empleo o mejora de empleo cuando se encuentren en edad laboral, salvo las excepciones establecidas en la presente Ley; e) disponer todas las condiciones y medios necesarios y suficientes para que los destinatarios menores de edad reciban la educación obligatoria; f) no practicar la mendicidad (Castilla y León. Decreto Ley 1/2014, de 27 de febrero, art. 13.2).

En esta línea, la consideración de derecho subjetivo que plantea el sistema de rentas mínimas de Castilla y León se aplica únicamente a aquellos beneficiarios que cumplan con lo dispuesto en el contenido obligacional de la prestación. Esta práctica, restrictiva de la libertad individual, podría suponer una estrategia de normalización y de adquisición de un modelo socioeconómico concreto si no se establecen mecanismos para garantizar el consenso y la coproducción de dichas obligaciones con los beneficiarios, tal como queda reflejado en este fragmento de una de las fuentes analizadas:

Según el artículo 13.9 del Estatuto de Autonomía, el disfrute de la prestación queda sujeto a los requisitos y condiciones que normativamente se dispongan. Por ello, no obstante el carácter de derecho subjetivo de la renta garantizada de ciudadanía y la observancia del principio de universalidad que rige la misma, resultará exigible para su disfrute el cumplimiento efectivo de las obligaciones generales que se impongan y de las específicas que contenga el proyecto individualizado de inserción que, como convenio obligacional, ha de ser suscrito por el titular (Castilla y León. Decreto Ley 1/2014, de 27 de febrero, exposición de motivos).

\section{Discusión}

A pesar de no ser ésta una afirmación concluyente, el mundo es como nosotros mismos lo construimos. Las diferencias individuales, aquellas que nos identifican como miembros de un determinado grupo, son perceptibles a través del discurso e implican comportamientos y formas de actuar, pues el lenguaje es una forma de acción. En la gran mayoría de las ocasiones, no somos conscientes de estas circunstancias, y es muy posible que estos comportamientos y acciones hayan sido fijados por la política y los grupos dominantes, con los riesgos que ello conlleva.

Las relativamente recientes políticas autonómicas dirigidas a la puesta en marcha de sistemas de rentas mínimas han permitido articular respuestas a la crisis de las economías capitalistas de bienestar, aunque con un carácter muy heterogéneo, ya que "a pesar de que sus cuantías básicas sean similares, la intensidad protectora es muy diversa entre las comunidades autónomas" (Arriba, 2009: 99). Entre las ventajas de las rentas mínimas, Moreno Márquez (2008) destaca su utilidad como instrumento paliativo en situaciones de pobreza extrema y como complemento para la intervención a través de itinerarios de inserción social. A través del análisis de las fuentes utilizadas, vemos cómo el discurso de los sistemas de rentas mínimas de Andalucía y Castilla y León se orienta hacia formas que a veces distan de lo planteado en las propias normas que los regulan. Los repertorios identificados nos muestran una importante desco- 
nexión entre lo regulado y el relato discursivo, lo que en ocasiones nos lleva hacia políticas de 'canto de sirena'.

Apreciamos una metodología que huye de formas de trabajo basadas en la potenciación y el fortalecimiento de personas, grupos y comunidades, y que tiene en cuenta el contexto social, hacia otros de tipo asistencial y eminentemente individual y de carácter paliativo, lo que va en contraposición al relanzamiento de la intervención comunitaria en los países de nuestro entorno (Casado y Fantova, 2007). Este fenómeno puede verse acrecentado por la cada vez más importante instrumentalización y politización de los sistemas de servicios sociales, en los que se incluyen los sistemas de rentas mínimas. Este fenómeno no es un hecho aislado y confirma la tesis de Aberbach, Putnam y Rockman (1981: 16) que sostiene que unos y otras han ido confluyendo hasta hablar de una "politización de la burocracia y una burocratización de la política”, $y$, por tanto, se trata de una relación recíproca y bidireccional.

Esta burocratización es además un importante dilema ético al que deben enfrentarse en su trabajo los profesionales de la acción social encargados de la puesta en práctica de los sistemas de rentas mínimas, evitando el riesgo de incurrir en actitudes de corte paternalista o que se alejan de las ideas metodológicas de la intervención social. Como sostienen Idareta-Goldaracena y Ballestero-Izquierdo (2013: 32), “cuando el profesional cumple obediente y acríticamente con las tareas encomendadas por la institución altamente burocratizada, tiende a relacionarse con la idea que se compone del usuario más que con el usuario en sí".

Otro elemento importante que debemos tener en cuenta, a pesar de su inexistencia en el discurso, son los cambios que en materia de servicios sociales introduce la reforma de la legislación de régimen local, con especial atención a aquellos que se prestan desde los ayuntamientos y diputaciones. Sobre esto, diversos autores sostienen que el nuevo marco competencial de los servicios sociales de carácter municipal va a centrarse, a diferencia del actual, en las prestaciones de carácter básico, dejando a un lado intervenciones más especializadas (Miguez, Almeida y Santiago, 2013). Otros riesgos destacables son la externalización y la privatización de determinados servicios, provocados por la pérdida del carácter de responsabilidad pública y su forma de gestión directa (Uceda et al., 2013).

La reforma local va a tener, sin lugar a dudas, repercusiones sobre la ya frágil colaboración existente entre la comunidad autónoma y las entidades locales para el desarrollo y evaluación de los sistemas de rentas mínimas, colaboración que, como hemos visto a través del discurso, queda contemplada, pero no desarrollada ni articulada para el logro de unos compromisos asumibles entre todas las administraciones implicadas.
Es importante resaltar que, del análisis realizado, se deduce una importante carencia en los sistemas de rentas mínimas descritos: la necesidad de procurar la incorporación del enfoque de resiliencia en la práctica profesional que se lleva a cabo en los sistemas de rentas mínimas. Siguiendo a Villalba (2006: 489), este enfoque "va más allá de la resolución de los problemas, ocupándose de su prevención, no sólo mediante la reparación actual, sino también preparando a los individuos y familias para retos futuros".

Un sistema que pretenda marcarse como objetivos la prevención y la reducción del riesgo de exclusión debe pasar por adaptar la respuesta que ofrecen las organizaciones que lo componen para el cumplimiento de objetivos, entendiendo este concepto como los esfuerzos y estrategias que deben poner en práctica para conseguir un mejor ajuste con el entorno y garantizarse la supervivencia (Linnenluecke, Griffiths y Winn, 2012). El actual contexto económico ha puesto de manifiesto cómo los sistemas de protección social y las estrategias de dirección de éstos no están preparados para adecuar su respuesta a las nuevas problemáticas sociales, por lo que fracasan en el logro de sus fines. De esta forma, el desarrollo de una estrategia organizacional orientada a fomentar la resiliencia de las personas y la capacidad de las comunidades para superar las dificultades son claves para el éxito de los sistemas de rentas mínimas y del sistema de servicios sociales en general, y debe tratarse de una cualidad deseable y perseguida por quienes ejercen la dirección en las organizaciones (Lampel, Bhalla y Jha, 2014).

Para concluir, una consideración. Nos resistimos a considerar un declive la situación actual del trabajo social, debida a los cambios políticos e institucionales descritos previamente. No hemos de ver un agotamiento del modelo de trabajo social llevado hasta el momento, sino más bien una oportunidad para revertir las tendencias previstas y para re-diseñar nuevos escenarios. La intervención actual en trabajo social busca trazar una única senda hacia el bienestar social, pasando por tres enclaves:

- La política social, como intervención de las administraciones públicas con la intención de compensar, redistribuir y remover los obstáculos al bienestar social.

- Los servicios sociales, como instrumentos que materializan las políticas sociales en aras a gestionar los problemas sociales de los ciudadanos.

- La promoción del cambio y el desarrollo social, la cohesión social, y el fortalecimiento y la liberación de las personas, involucrándolas para hacer frente a los desafíos e incrementar el bienestar, tal como establece la Federación Internacional de Trabajo Social a la hora de definir esta disciplina (2014). En este sentido, el trabajo social tiene un cuerpo teórico, metodológico y deontológico propio, conectado con los derechos humanos, sociales y la justicia social. Por tanto, su alcance es superior al dictado del contexto sociopolítico. 
La oportunidad del trabajo social reside en la capacidad de ejecutar las acciones políticas en el contexto de los servicios sociales, en contacto y en conexión con la ciudadanía. La influencia del trabajo social en la fase de creación y expansión de los servicios sociales democráticos fue clave. Ahora, vivimos un punto de inflexión en la historia de éstos, y el trabajo social tiene una responsabilidad clara al respecto, si bien, en la actualidad, goza de un estatus y unas estructuras con las que no contaba en el pasado.

Ha sido intencionada la elección del término 'sistemas de rentas mínimas' en este estudio, frente al usado en otros momentos de 'rentas mínimas de inserción'. Queremos poner el acento en el concepto de sistema y en lo que éste conlleva. El término 'sistema' nos lleva al de 'red'. La definición de los sistemas de servicios sociales de Andalucía y Castilla y León como sistemas de responsabilidad pública implica que sus actores trabajen como una unidad cohesionada y coordinada, compartiendo una visión, unos valores y una única misión. El trabajo en red crea sinergias entre los agentes públicos y privados, y la comunidad implicada.

La aportación de nuestra investigación, tras el análisis descrito, nos hace centrar la atención en un modelo de gestión de los sistemas de rentas mínimas desde los principios y valores del trabajo social. También nos parece acertado destacar la importancia de nuestra profesión en las rentas mínimas a escala micro, no sólo en las fases de seguimiento y reinserción social, sino en las propias de la definición de la prestación a las personas beneficiarias, reforzando la actuación profesional. Ejemplos de ello pueden ser arbitrar cuantías personalizadas y variables, adaptadas a la situación sociofamiliar de cada momento; ofertar la inter- vención profesional como alternativa o complemento a la prestación, y construir el proceso de reinserción con los interesados, desvinculándolo del contenido obligacional; o reforzar la acción comunitaria de las personas perceptoras como acciones inclusivas que creen conciencia de colectividad. Con ello, logramos un trabajo social más creativo y proactivo, capaz de centrarse en las redes naturales que conforman el apoyo social de las personas perceptoras, activándolas, dinamizándolas desde la autonomía y el empoderamiento. Ello contribuye a incrementar el capital personal y social de la persona o familia, y, por extensión, de su red social y comunitaria.

Ponemos el acento en el sistema más que en la inserción, avanzando en la eficacia de lo público, lo local y lo profesional del trabajo social. Evitamos centrarnos en la persona y en sus carencias, para hacerlo en sus circunstancias y sus potencialidades. En la actualidad, la garantía de los sistemas de rentas mínimas ha de converger hacia los derechos subjetivos, ha de residir en la gestión por la función pública, capaz de aplicar las políticas sociales desde la igualdad y de velar por una gestión que contribuya al bienestar social. La proximidad a la ciudadanía, la participación de la comunidad y de las personas implicadas, su legitimidad son bases de la democracia local y de la corresponsabilidad ciudadana con los asuntos de la comunidad, y nos aproxima a formas de hacer copolíticas. No cabe en un Estado no actuar conforme a los derechos. La actuación profesional del trabajo social, así como la pervivencia y desarrollo de los servicios sociales son un derecho de la ciudadanía. La refilantropización de lo social es un gasto y un desgaste para el sistema de servicios sociales. La desprofesionalización de éste es una tendencia que la profesión y la ciudadanía debemos revertir. 
ABERBACH, J. D.; PUTNAM, R. D.; y ROCKMAN, B. A. (1981): Bureaucrats and Politicians in Western Democracies, Cambridge, Harvard University Press.

ANDALUCÍA (2013): “Decreto Ley 7/2013, de 30 de abril, de medidas extraordinarias y urgentes para la lucha contra la exclusión social en Andalucía", Boletín Oficial de la Junta de Andalucía, no 85, 3-5-2013, págs. 27-88 [<http://www. juntadeandalucia.es/boja/2013/85/BOJA13085-00062-7379-01_00026320.pdf >].

- (1999): “Decreto 2/1999, de 12 de enero, por el que se regula la creación del Programa de Solidaridad de los Andaluces para la Erradicación de la Marginación y la Desigualdad", Boletín Oficial de la Junta de Andalucía, no 16, 6-2-1999, págs. 1.531-1.536 [<http://www. juntadeandalucia.es/boja/1999/16/d8.pdf〉].

ARRIBA, A. (2009): "Rentas mínimas de inserción de las comunidades autónomas: una visión conjunta de su evolución y alcance", Gestión y Análisis de Políticas Públicas, no 2, págs. 81-100.

BARRERA-ALGARÍN, E.; MALAGÓN-BERNAL, J. L.; y SARASOLA-SÁNCHEZ-SERRANO, J. L. (2013): "La deconstrucción del Estado de bienestar: cambios en el ejercicio profesional de los trabajadores sociales y aumento del voluntariado social", Cuadernos de Trabajo Social, vol. 26, nํㅜ 1, págs. 115-126 [<http:// dx.doi.org/10.5209/rev_CUTS.2013.v26. n1.39272>].

CASADO, D.; y FANTOVA, F. (2007): Perfeccionamiento de los servicios sociales en España: informe con ocasión de la Ley sobre Autonomía y Dependencia, colección Estudios, nํㅜㄱ, Madrid, Cáritas Española Editores; Fundación Foessa.
CASTILLA Y LEÓN (2014): “Decreto Legislativo 1/2014, de 27 de febrero, por el que se aprueba el texto refundido de las normas legales vigentes en materia de condiciones de acceso y disfrute de la prestación esencial de renta garantizada de ciudadanía de Castilla y León”, Boletín Oficial de Castilla y León, no 42, 3-3-2014, págs. 14.058-14.079 [rhttp:// bocyl.jcyl.es/boletines/2014/03/03/pdf/ BOCYL-D-03032014-1.pdf>].

- (2010): “Decreto 61/2010, de 16 de diciembre, por el que se aprueba el reglamento de desarrollo y aplicación de la renta garantizada de ciudadanía”, Boletín Oficial de Castilla y León, no 243, 20-12-2014, págs. 96.671-96.691 [<http://bocyl.jcyl.es/boletines/2010/12/20/ pdf/BOCYL-D-20122010-8.pdf>].

CONSEJO ECONÓMICO Y SOCIAL DE CASTILLA Y LEÓN (2014): Informe sobre la Situación Económica y Social de Castilla y León en 2013, Valladolid, Consejo Económico y Social de Castilla y León.

ESPAÑA (2013): “Ley 27/2013, de 27 de diciembre, de racionalización y sostenibilidad de la Administración Local”, Boletín Oficial del Estado, no 312, 30-12-2013, págs. 106.430106.473 [/https://www.boe.es/diario_boe/txt. php?id=BOE-A-2013-13756>].

- (1985) "Ley 7/1985, de 2 de abril, Reguladora de las Bases del Régimen Local”, Boletín Oficial del Estado, $\mathrm{n}^{0} 80$, 3-4-1985, págs. 8.9458.964 [khttps://www.boe.es/diario_boe/txt. php?id=BOE-A-1985-5392>].

- (1978): “Constitución Española”, Boletín Oficial del Estado, n- 311, 29-12-1978, págs. 29.31329.424 ['https://www.boe.es/buscar/doc. php?id=BOE-A-1978-31229>]. 
FEDERACIÓN INTERNACIONAL DE TRABAJO SOCIAL (2014): "Global Definition of Social Work" [aprobada por la Asamblea General de la International Federation of Social Workers en Melbourne (Australia), el 6 de julio de 2014] [<http://ifsw. org/get-involved/global-definition-of-socialwork/>].

IDARETA-GOLDARACENA, F.; y BALLESTERO-IZQUIERDO, A. (2013): "Ética, paternalismo y burocracia en Trabajo Social”, Portularia. Revista de Trabajo Social, vol. 13, n- 1, págs. 27-35 [<http://dx.doi. org/10.5218/prts.2013.0004'].

INSTITUTO DE ESTADÍSTICA Y CARTOGRAFÍA DE ANDALUCÍA (s. d.): [rhttp://www.juntadeandalucia.es/ institutodeestadisticaycartografia/temas/ temao2.html >].

JUNTA DE ANDALUCÍA. CONSEJERÍA DE IGUALDAD, SALUD Y POLÍTICAS SOCIALES (s. d.): "Ingreso Mínimo de Solidaridad (Programa de solidaridad)" [<http://www.juntadeandalucia.es/ organismos/igualdadsaludypoliticassociales/ areas/inclusion/programa-solidaridad.html/].

- (s. d.): "Servicios Sociales. Salario Social" [ <http://www. juntadeandalucia.es/salud/sites/csalud/ contenidos/Informacion_General/c_3_c_9_ preguntas_frecuentes/servicios_sociales〉].

JUNTA DE CASTILLA Y LEÓN. SERVICIOS SOCIALES (s. d.): "Renta Garantizada de Ciudadanía", Junta de Castilla y León [«http://www. jcyl.es/web/jcyl/ServiciosSociales/es/ Plantilla10o/1281175640040/_ / / ].

LAMPEL, J.; BHALLA, A.; y JHA, P. P. (2014): “Does governance confer organisational resilience? Evidence from UK employee owned businesses", European Management Journal, vol. 32, no 1, págs. 66-72 [<http://dx.doi.org/10.1016/j. emj.2013.06.009>].

LAPARRA, M.; y PÉREZ ERANSUS, B. (2010): El primer impacto de la crisis en la cohesión social en España, colección Estudios, no 32, Madrid, Fundación Foessa; Cáritas Española Editores.

LINNENLUECKE, M. K.; GRIFFITHS, A.; y WINN, M. (2012): "Extreme weather events and the critical importance of anticipatory adaptation and organizational resilience in responding to impacts", Business Strategy and the Environment, vol. 21, n- 1, págs. 17-32 [rhttp:// dx.doi.org/10.1002/bse.708>].

MARSHALL, T. H. (1997) [1949]: “Ciudadanía y clase social”, Revista Española de Investigaciones Sociológicas, nํㅜㄱ, págs. 297-344.

MIGUEZ, L.; ALMEIDA, M.; y SANTIAGO, D. (2013): “Crisis del Estado de bienestar y servicios públicos locales: ¿de los servicios sociales a la asistencia social primaria?" [comunicación], XIX Congreso ItaloEspañol de Derecho Administrativo, Madrid, 18 a 20 de octubre de 2012

MORENO, L. (2012): La Europa asocial. ¿Caminamos hacia un individualismo posesivo?, serie Atalaya, Barcelona, Península.

- (2000): Ciudadanos precarios. La 'última red' de protección social, serie Sociología, Barcelona, Ariel.

MORENO MÁRQUEZ, G. (2008): “La reformulación del Estado del bienestar: el workfare, las políticas activas de empleo y las rentas mínimas", Zerbitzuan. Revista de Servicios Sociales, no- 43, págs. 143154 [<http://www.zerbitzuan.net/documentos/ zerbitzuan/Reformulaicon\%2odel\%20 Estado\%2odel\%2obienestar.pdf $>$ ].

PACHECO-MANGAS, J.; y HERNÁNDEZ-ECHEGARAY, A., (2014): “Las rentas mínimas, ¿un soporte para la ciudadanía en la crisis de los Estados de Bienestar?: un análisis comparado entre Andalucía y Castilla y León", en CABISE 2014. Revaluando el Estado de bienestar en el sur de Europa, Oviedo, Departamento de Sociología de la Universidad de Oviedo, págs. 487-503 [<http://congresocabise2014.com/ libroactas2014.pdf\#page $=487 \mathrm{\nu}$.

RUIZ OLABUÉNAGA, J. I.; e ISPIZUA, M. A. (1989): La decodificación de la vida cotidiana: métodos de la investigación cualitativa, Bilbao, Universidad de Deusto.

TEZANOS, J. F. et al. (2013): En los bordes de la pobreza. Las familias vulnerables en contextos de crisis, Madrid, Biblioteca Nueva.

- (2008): "Exclusión social, democracia y ciudadanía económica. La libertad de los iguales", Revista del Ministerio de Trabajo y Asuntos Sociales, no -75 , págs. $17-29$.

UCEDA, F. X. et al. (2014): "La pérdida de garantía en los Servicios Sociales Comunitarios: la reforma local", Azarbe. Revista Internacional de Trabajo Social y Bienestar, no 3, págs. 247-251.

UCEDA, F. X. et al. (2013): "Els Serveis Socials Municipals en risc de desaparició", TSNova. Trabajo Social y Servicios Sociales, vol. 7, ํํ1, págs. 73-86.

VILLALBA, C. (2006): "El enfoque de resiliencia en trabajo social", Acciones e Investigaciones Sociales, no extra 1, págs. 466-495.

WETHERELL, M.; y POTTER, J. (1996): “El análisis del discurso y la identificación de los repertorios interpretativos", en GORDO, A.; y LINAZA, J. (eds.), Psicologías, discursos y poder, Madrid, Visor, págs. 63-78. 